\title{
Produção e renda bruta de dois cultivares de taro, em cultivo solteiro e consorciado com alface
}

\section{Yield and gross income of two cultivars of taro in monocrop and intercrop systems with lettuce}

\author{
Néstor Antonio Heredia Zárate ${ }^{1 *}$; Maria do Carmo Vieira ${ }^{2}$; \\ Antonio Carlos Peixoto de Oliveira ${ }^{3}$; Andréa Alves de Lima ${ }^{4}$
}

\begin{abstract}
Resumo
O objetivo do trabalho foi determinar a capacidade produtiva e a renda bruta dos cultivares de taro 'Chinês' e 'Macaquinho', sob cultivo solteiro e consorciado com a alface 'Grand Rapids Nacional', visando oferecer aos agricultores nova alternativa de produção. A colheita da alface realizou-se aos 57 dias após a semeadura e a dos taros, aos 285 dias após o plantio. As massas fresca e seca da parte aérea das plantas de alface não foram influenciadas significativamente pelo sistema de cultivo. A massa fresca da parte aérea das plantas do taro 'Chinês' $\left(7,43 \mathrm{t} \mathrm{ha}^{-1}\right)$ foi significativamente maior em 1,46 tha ${ }^{-1}$ à do 'Macaquinho', mas não foi afetada pela forma de cultivo. A massa fresca de rizomas-mãe do 'Macaquinho' superou em 5,83 tha-1 à do 'Chinês'. A massa fresca de rizoma-filho comercial grande do 'Macaquinho' $\left(23,30 \mathrm{t} \mathrm{ha}^{-1}\right)$ foi significativamente maior que a do 'Chinês', mas com a massa fresca de rizoma-filho comercial pequeno ocorreu o inverso. Os dois consórcios foram viáveis economicamente, mas, o consórcio alface $\mathrm{x}$ taro 'Macaquinho' foi o melhor ( $\mathrm{R} \$ 83.664,00 \mathrm{ha}^{-1}$ ), porque poderia ter induzido ganho de $\mathrm{R} \$ 50.664$ $\mathrm{ha}^{-1} \mathrm{em}$ relação à alface solteira e de $\mathrm{R} \$ 21.768 \mathrm{ha}^{-1}$, em relação ao consórcio da alface x taro 'Chinês'.

Palavras-chave: Colocasia esculenta, Lactuca sativa, associação de culturas, produtividade, lucro
\end{abstract}

\begin{abstract}
The objective of this work was to determine yield capacity and gross income of 'Chinês' and 'Macaquinho' taro cultivars under monocrop and intrercrop systems with 'Grand Rapids Nacional' lettuce in order to offer to producers a new alternative of production. Harvest of lettuce was done on 57 days after sowing and of taro on 285 days after planting. Fresh and dried masses of aerial parts of lettuce plants were not influenced significantly by the cultivation system. Fresh mass of aerial parts of 'Chinês' taro plants was significantly higher in $1.46 \mathrm{t} \mathrm{ha}^{-1}$ than 'Macaquinho', but it was not affected by cultivation system. Fresh mass of 'Macaquinho' corms was superior in 5.83 t ha $^{-1}$ compared with 'Chinês'. Fresh mass of big commercial cormel of 'Macaquinho' (23.30 tha $\left.\mathrm{t}^{-1}\right)$ was significantly higher than "Chinês", but with fresh mass of small commercial cormel occurred the inverse. Both two consortia were economic viable, but lettuce/'Macaquinho' taro consortium was the best $\left(\mathrm{R} \$ 83,664.00 \mathrm{ha}^{-1}\right)$, because it can induce a gain of $\mathrm{R} \$$ $50,664 \mathrm{ha}^{-1}$ in relation to monocrop of lettuce, and a gain of $\mathrm{R} \$ 21,768 \mathrm{ha}^{-1}$ in relation to lettuce/'Chinês' taro consortium.
\end{abstract}

Key words: Colocasia esculenta, Lactuca sativa, intercrop, productivity, income

1 Professor Adjunto e bolsista de Produtividade em Pesquisa do CNPq. Universidade Federal de Mato Grosso do Sul, Departamento de Ciências Agrárias, C. Postal 533, CEP 79804-970 - Dourados-MS. E-mail: nheredia@ceud.ufms.br

2 Professor Titular e bolsista de Produtividade em Pesquisa do CNPq. Universidade Federal de Mato Grosso do Sul, Departamento de Ciências Agrárias, C. Postal 533, CEP 79804-970 - Dourados-MS. E-mail: mcvieira@ceud.ufms.br

3 Aluno do Curso de Agronomia da Universidade Federal de Mato Grosso do Sul. Bolsista de Iniciação Científica UFMS/CNPq.

4 Aluno do Curso de Ciências Biológicas da Universidade Federal de Mato Grosso do Sul. Bolsista de trabalho.

* Autor para correspondência.

Recebido para publicação 01/03/05 Aprovado em 26/08/05

Semina: Ciências Agrárias, Londrina, v. 26, n. 3, p. 283-290, jul./set. 2005 


\section{Introdução}

Estudos de consorciação de culturas estão contribuindo para que se descubra o quão mais avançada é a tecnologia da consorciação em relação ao monocultivo, quanto à sustentabilidade do ambiente, mediante a manutenção da biodiversidade, conservação do solo, reciclagem de nutrientes, controle de plantas daninhas, controle de pragas e doenças e aumento da produtividade (INNIS, 1997). Deve ser por isso que Sullivan (2001) cita que a produção agrícola é o resultado da ação integrada da planta e dos estímulos do meio ambiente, enquanto a produção consorciada é a interação entre culturas diferentes em condições necessárias para o seu desenvolvimento.

A associação/consorciação de culturas é um sistema de cultivo utilizado há séculos pelos agricultores (MÜLLER et al., 1998) e é praticado amplamente nas regiões tropicais, principalmente entre pequenos produtores (TOLENTINO JÚNIOR; HEREDIA ZÁRATE; VIEIRA, 2002). Innis (1997) relata que, os principais consórcios nas Américas são a combinação de milho (Zea mays L.) e feijão (Phaseolus vulgaris L); na África do milheto (Pennisetum glaucum L.) e feijão-caupi (Vigna unguiculata L.); no Leste Europeu o trigo (Triticum aestivum L.) e grão-de-bico (Cicer arietinum L.); na Índia o sorgo (Sorghum spp L.) e feijão andu (Cajanus cajan L.); na China o arroz (Oryza sativa L.) e soja (Glycine $\max$ L.) e na Europa usam-se a aveia (Avena sativa L.), ervilha (Pisum sativum L.), cevada (Hordeum vulgare L.) e feijão.

No Brasil, pequenos agricultores geralmente cultivam diversas espécies associadas às de milho, cana-de-açúcar, café e outras. Na região de Campos, RJ, na cultura da cana-de-açúcar, muitas vezes é feito intercultivo de abóbora, milho e feijão. Em Goiânia, com finalidade de sombreamento, foi observado um caso de utilização de consórcio de couve comum com alface e cenoura, cultivadas em canteiro cuja margem, voltada para o sol da tarde, cultivava-se uma linha de couve. Em casos como esse, o objetivo do consórcio não é a obtenção de maior produtividade, mas a melhoria da qualidade comercial do produto. A consorciação tem despertado a atenção de inúmeros pesquisadores, os quais vêm estudando aspectos desse sistema cultural, como arranjo, densidade e época de semeadura das culturas, fertilização e identificação de cultivares mais adaptados (INNIS, 1997; CAETANO; FERREIRA; ARAUJO, 1999; TOLENTINO JÚNIOR; HEREDIA ZÁRATE; VIEIRA, 2002; SALVADOR, 2003, VIEIRA; HEREDIA ZÁRATE; GOMES, 2003).

Caetano, Ferreira e Araujo (1999), relatam que conduziram dois experimentos para estudar a alface e a cenoura, em monocultivo e em consórcio, e observaram que ambas culturas apresentaram produção adequada para comercialização, apenas houve prejuízo à cenoura no sistema de consórcio quando esta foi cultivada com a alface 'Marisa'. Os valores de 1,74 e 1,76 para a Razão de Área Equivalente (RAE), evidenciaram que a utilização do consórcio foi vantajosa nos dois experimentos. Tolentino Júnior, Heredia Zárate e Vieira (2002), estudando a produção da mandioquinha-salsa 'Amarela de Carandaí' consorciada com alface 'Grand Rapids' e beterraba 'Tal Top Early Wonder', observaram que as plantas das três espécies tiveram produtividade superior em monocultivo. Esse resultado foi relacionado com a menor competição e melhor aproveitamento do solo quando as plantas estão em sistema solteiro. Entretanto, ao considerar a produção total de raízes e a de raízes comerciais, a RAE para o consórcio mandioquinha-beterraba foi de 1,07 e 0,87 e para mandioquinha-alface foi 1,3 e 1,1 , respectivamente.

$\mathrm{Na}$ literatura consultada, não foram encontrados relatos sobre o consórcio de Colocasia esculenta (L.) Schott (taro) com Lactuca sativa Mill. (alface). O taro, por suas características nutricionais tem possibilidades de uso humano sob diferentes formas de preparo, podendo substituir, total ou parcialmente, a batatinha, a mandioca, o milho, o trigo e outras espécies amídicas (ABRAMO, 1990; ANUÁRIO..., 
1994). Também pode ser utilizado na alimentação animal, especialmente para frangos de corte (HEREDIA ZÁRATE; VIERA; GOMES, 2001). A cultura de taro é de ocorrência comum nos trópicos úmidos e sua importância reside no seu valor alimentar e forma de consumo, ao natural ou processado, e na capacidade de as plantas produzirem em condições consideradas impróprias para a agricultura tradicional, como pantanais e áreas alagadiças. Esta habilidade para produzir, tanto em locais secos como alagados, faz dessa espécie a cultura de subsistência ideal para áreas onde não se usa tecnologia avançada (HEREDIA ZÁRATE, 1995; HEREDIA ZÁRATE; VIEIRA; SILVA, 1997). Contudo, a produtividade é grandemente variável por causa das diferenças nas práticas de plantio e por desconhecimento das características genotípicas das diferentes espécies e cultivares (HEREDIA ZÁRATE; YAMAGUTI, 1994). Dentre os cultivares de taro estudados em Dourados, para comercialização ao natural, tanto em condições de solo sempre úmido como de época seca do pantanal sul-matogrossense, sempre sobressaíram os cultivares Japonês, Macaquinho e Chinês, na sua ordem, por apresentarem altas percentagens de rizomas-filho, com pesos superiores a $25 \mathrm{~g}$ e com formatos regulares, ovóides e arredondados.

A alface (Lactuca sativa) é uma hortaliça popular no mundo inteiro (FILGUEIRA, 2000) e cultivada tradicionalmente no território brasileiro. Os volumes de produção e de consumo são grandes (BARBOSA, 1999). Na alface deve-se destacar o elevado teor de vitamina A nas folhas verdes, alcançando até 4.000 UI/100g. O Estado de São Paulo é o maior produtor, com aproximadamente 7.300 ha, ocupando no Brasil o sétimo lugar em área cultivada, entre as hortaliças (TRANI et al., 1997). No Mato Grosso do Sul, em 1996, a área cultivada com alface foi de 203 ha e no município de Dourados foi a hortaliça folhosa de maior área, de 65 ha (DIAGNÓSTICO..., 1998). A planta tem ciclo curto (60 a 80 dias) e sistema radicular pouco profundo (FILGUEIRA, 2000).

Em razão do exposto, o objetivo do trabalho foi determinar a capacidade produtiva e a renda bruta dos cultivares de taro 'Chinês' e 'Macaquinho', sob cultivo solteiro e consorciado com alface, visando oferecer aos agricultores nova alternativa de produção.

\section{Material e Métodos}

O experimento foi conduzido em área do Horto de Plantas Medicinais, do Núcleo Experimental de Ciências Agrárias, da Universidade Federal do Mato Grosso do Sul, em Dourados-MS, entre 12-9-2003 e 23-6-2004. O município de Dourados situa-se em latitude de $22^{\circ} 13^{\prime} 16^{\prime}$ 'S, longitude de $54^{\circ} 17^{\prime} 01^{\prime \prime} \mathrm{W}$ e altitude de $430 \mathrm{~m}$. O clima da região, segundo a classificação de Köppen, é Mesotérmico Úmido; do tipo Cwa, com temperaturas e precipitações médias anuais variando de $20^{\circ}$ a $24^{\circ} \mathrm{C}$ e de $1250 \mathrm{~mm}$ a 1500 $\mathrm{mm}$, respectivamente. Os dados climáticos, na época de desenvolvimento do experimento, são apresentados na Tabela 1. O solo é do tipo Latossolo Vermelho distroférrico, com as seguintes características químicas: $\mathrm{pH}$ em água $=6,4 ; \mathrm{M} . \mathrm{O} .=$ $23,4 \mathrm{~g} \mathrm{dm}^{-3} ; \mathrm{P}=45 \mathrm{mg} \mathrm{dm}^{-3}$; e 5,6; 0,0; 54,0 e 21,6 $\mathrm{mmol}_{\mathrm{c}} \mathrm{dm}^{-3}$ de $\mathrm{K}, \mathrm{Al}, \mathrm{Ca}$ e $\mathrm{Mg}$, respectivamente.

Tabela 1 - Médias mensais de temperatura e umidade relativa e precipitação acumulada mensal no ciclo do experimento.

\begin{tabular}{|c|c|c|c|c|c|c|c|}
\hline $\begin{array}{l}\mathbf{2 0 0 3} \\
\text { (Mês) }\end{array}$ & $\begin{array}{c}\text { Temperatura } \\
\text { média } \\
\left({ }^{\circ} \mathrm{C}\right)\end{array}$ & $\begin{array}{c}\text { Umidade } \\
\text { Relativa } \\
(\%)\end{array}$ & $\begin{array}{l}\text { Precipi- } \\
\text { tação } \\
(\mathrm{mm})\end{array}$ & $\begin{array}{l}\mathbf{2 0 0 4} \\
\text { (Mês) }\end{array}$ & $\begin{array}{c}\text { Temperatura } \\
\text { média } \\
\left({ }^{\circ} \mathrm{C}\right)\end{array}$ & $\begin{array}{c}\text { Umidade } \\
\text { Relativa } \\
(\%)(\%)\end{array}$ & $\begin{array}{c}\text { Precipi- } \\
\text { tação } \\
(\mathrm{mm})\end{array}$ \\
\hline Setembro & 21,01 & 62,83 & 101,6 & Janeiro & 25,35 & 72,85 & 117,3 \\
\hline Outubro & 23,34 & 67,57 & 171,5 & Fevereiro & 24,89 & 68,51 & 61,7 \\
\hline Novembro & 24,35 & 64,80 & 106,4 & Março & 24,91 & 65,57 & 61,0 \\
\hline \multirow[t]{3}{*}{ Dezembro } & 25,28 & 74,66 & 123,2 & Abril & 23,75 & 77,31 & 141,7 \\
\hline & & & & Maio & 16,91 & 85,36 & 313,8 \\
\hline & & & & Junho & 17,75 & 78,61 & 136,7 \\
\hline
\end{tabular}


Foram estudados os cultivares de taro Macaquinho e Chinês, com duas linhas por canteiro, tanto no cultivo solteiro como no consórcio com alface 'Grand Rapids Nacional', com quatro linhas de plantas (Figura 1), arranjados no delineamento experimental de blocos casualizados, com quatro repetições. As parcelas tiveram área total de $3,60 \mathrm{~m}^{2}(1,5 \mathrm{~m}$ de largura por 2,4 $\mathrm{m}$ de comprimento), sendo que a largura efetiva do canteiro foi $1,08 \mathrm{~m}$. Para alface utilizou-se espaçamento de 0,20 m entre plantas e de $0,27 \mathrm{~m}$ entre linhas. No consórcio, os espaçamentos foram de 0,135 m entre linhas, independendo da espécie.

AAAAAAAAAAAAAAAA
AAAAAAAAAAAAAAAA
AAAAAAAAAAAAAAAA
AAAAAAAAAAAAAAAA

Alface solteiro

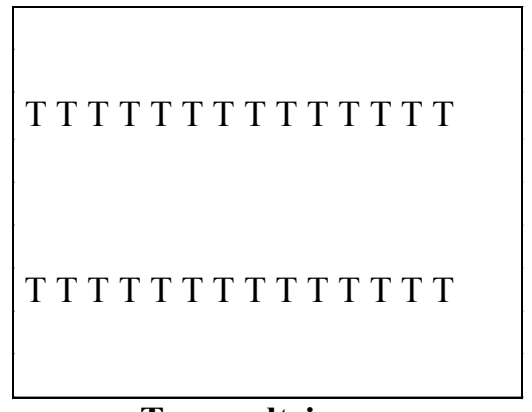

Taro solteiro

AAAAAAAAAAAAAAAA
T T T T T T T T T T T T T T
AAAAAAAAAAAAAAAA
AAAAAAAAAAAAAAAA
T T T T T T T T T T T T T T
AAAAAAAAAAAAAAAA

Consórcio alface com taro

Figura 1. Arranjo de plantas de alface com as de taro 'Macaquinho' ou 'Chinês, como culturas solteiras e consorciadas. Dourados, UFMS, 2003-2004

O terreno foi preparado com trator, duas semanas antes da semeadura, com uma aração e uma gradagem e, posteriormente, foram levantados os canteiros com rotoencanteirador. Para a semeadura de alface foram abertos sulcos de dois centímetros de largura e um centímetro de profundidade. A semeadura foi manual, colocando-se três ou quatro sementes por cova. Posteriormente, as sementes foram cobertas com cama-de-frango semidecomposta. Quinze dias após a emergência, fez-se o desbaste para deixar uma planta por cova. Para o plantio dos taros 'Macaquinho' e 'Chinês', foram abertos sulcos de aproximadamente $0,10 \mathrm{~m}$ de largura $\mathrm{x} 0,15 \mathrm{~m}$ de profundidade, a $0,27 \mathrm{~m}$ nos dois lados do canteiro. As mudas para o plantio foram rizomas-filho inteiros grandes (peso médio de 68,3 $\mathrm{g}$ ) e pequenos $(28,5 \mathrm{~g})$, que foram colocados no fundo dos sulcos, com os ápices para cima, e posteriormente cobertos com a terra extraída. Cada classe de rizoma foi utilizada para duas repetições, para otimizar o material propagativo.

As irrigações foram feitas utilizando o sistema de aspersão, sendo que na fase inicial, até as plantas apresentarem em torno de $0,10 \mathrm{~m}$ de altura, os turnos de rega foram diários e, posteriormente, a cada dois dias. Durante o ciclo das culturas foram feitas capinas com enxada, entre os canteiros, e manualmente, nos canteiros. Não houve infestações de pragas ou infecção de doenças.

A colheita da alface foi realizada após 57 dias da semeadura, quando os caules das plantas apresentavam início de alongamento, o que antecede o pendoamento, e quando as folhas ainda estavam suculentas e sem sabor amargo, ocasião em que foram avaliadas as massas fresca e seca das partes aéreas e a relação massa fresca : massa seca. A colheita dos taros foi aos 285 dias após o plantio, quando mais de $50 \%$ da parte aérea das plantas apresentavam-se amareladas e secas, sintomas típicos de senescência. Os caracteres avaliados foram massas frescas da parte aérea (limbos + pecíolos), dos rizomas-mãe-RM e dos rizomas-filhoRF comerciais (massa superior a 25,0 g) e RF nãocomerciais. Os dados foram submetidos à análise de variância e quando o teste $\mathrm{F}$ foi significativo, a $5 \%$ de probabilidade, aplicou-se o teste Tukey, para diferenciação das médias. 
O consórcio foi avaliado utilizando a expressão da razão de área equivalente (RAE) proposta por Caetano, Ferreira e Araújo (1999), a saber: RAE = $\mathrm{Ac} . \mathrm{As}^{-1}+\mathrm{Tc} . \mathrm{Ts}^{-1}$, onde, respectivamente, Ac e Tc $=$ produções da alface e do taro em consorciação e As e Ts $=$ produções da alface e do taro em cultivo solteiro. A validação do consórcio foi realizada mediante a determinação da renda bruta. Para isso, pesquisaram-se os preços pagos aos produtores, pelos vendedores varejistas de Dourados-MS, sendo $\mathrm{R} \$ 0,25$ por "pé" de alface e $\mathrm{R} \$ 1,20$ o kg de taro. Posteriormente, efetuaram-se as conversões por hectare da renda bruta, por cultivo e total.

\section{Resultados e Discussão}

As produções de massa fresca e seca da parte aérea das plantas da alface 'Grand Rapids Nacional' não foram influenciadas significativamente pelo sistema de cultivo (Tabela 2). As produções obtidas neste experimento, para massa fresca da alface (desde 19,92 $\mathrm{t} \mathrm{ha}^{-1}$ no consórcio com o taro 'Macaquinho' a 22,65 t ha ${ }^{-1}$ no cultivo solteiro) foram superiores às relatadas por Tolentino Júnior, Heredia Zárate e Vieira (2002), que trabalharam, entre 2 de junho e 7 de agosto de 1999, na mesma área e com a mesma cultivar de alface $\left(17,78 \mathrm{t} \mathrm{ha}^{-1}\right.$ no cultivo solteiro), com diferença no consórcio (14,58 tha-1), que foi com a mandioquinha-salsa 'Amarela de Carandaí'. Por outro lado, em relação ao ciclo vegetativo, foi reduzido em 10 dias, provavelmente, por terem sido cultivadas em época considerada quente (médias das temperaturas máximas de $28,0^{\circ} \mathrm{C}$ em setembro a $31,9^{\circ} \mathrm{C}$ em novembro). Esses resultados são coerentes com as citações de Filgueira (1972) de que altas temperaturas aceleram o desenvolvimento da planta de alface e encurtam o ciclo vegetativo. Também, confirmam o exposto por Larcher (2000) sobre os sistemas ecológicos serem capazes de se auto-regular com base no equilíbrio das relações de interferência.

A relação massa seca/massa fresca das alfaces consorciadas com o taro Macaquinho (4,52\%) superou em $0,41 \%$ e $0,69 \%$ às das alfaces cultivadas solteiras e no consórcio com o taro Chinês, respectivamente, confirmando a hipótese de que a partição dos fotoassimilados, sobretudo, é função do genótipo e das relações fonte-dreno (EMBRAPA, 1996; FANCELLI; DOURADO NETO, 1996) onde, provavelmente, a eficiência de conversão fotossintética, dentre outros fatores, dependa principalmente da temperatura, do estado nutricional e do equilíbrio hídrico das plantas (LARCHER, 2000). Isso porque, práticas como a escolha da cultivar para as condições prevalecentes na área e a forma de condução da cultura, dentre outras, podem alterar a produtividade (HEREDIA ZÁRATE, 1990b).

Tabela 2. Produção de massas fresca e seca de parte aérea de plantas de alface em cultivo solteiro e consorciadas com dois cultivares de taro. Dourados, UFMS, 2003-2004.

\begin{tabular}{lccc}
\hline Tratamentos & $\begin{array}{c}\text { Massa } \\
\text { Fresca } \\
\left(\mathrm{t} \mathrm{ha}^{-1}\right)\end{array}$ & $\begin{array}{c}\text { Massa Seca } \\
\left(\mathrm{t} \mathrm{ha}^{-1}\right)\end{array}$ & $\begin{array}{c}\text { MS:MF } \\
(\%)\end{array}$ \\
\hline $\begin{array}{l}\text { Alface } \\
\begin{array}{l}\text { Alface e taro } \\
\text { Macaquinho }\end{array}\end{array}$ & $19,92 \mathrm{a} \mathrm{a}^{\underline{1}}$ & $0,93 \mathrm{a}$ & 4,11 \\
$\begin{array}{l}\text { Alface e taro } \\
\text { Chinês }\end{array}$ & $21,91 \mathrm{a}$ & $0,90 \mathrm{a}$ & 4,52 \\
\hline C.V. $(\%)$ & 42,13 & 25,57 & 3,83 \\
\hline
\end{tabular}

${ }^{1 /} \mathrm{F}, 5 \%$ de probabilidade

A produção de massa fresca da parte aérea das plantas de taro 'Chinês' foi significativamente maior em 1,46 tha ${ }^{-1}$ em relação à do 'Macaquinho' (Tabela 3), mas não foi afetada pela forma de cultivo. Estes resultados possivelmente estejam relacionados com o fato de que as taxas de senescência das plantas de taro terem padrão de resposta dependente do componente genético. Todas as produções de massas frescas das partes aéreas das plantas foram semelhantes às obtidas com os mesmos cultivares em Viçosa-MG, em condições de solo seco e alagado (HEREDIA ZÁRATE, 1988); em condições de solo úmido do pantanal sul-mato-grossense (HEREDIA ZÁRATE, 1995) e sob irrigação por aspersão na microrregião de Dourados-MS (HEREDIA ZÁRATE; YAMAGUTI, 1994; HEREDIA ZÁRATE; VIEIRA; GOMES,1997). 
Tabela 3. Produção de parte aérea e de rizomas, mãe e filho, comercial e não comercial, de plantas de dois cultivares de taro e de plantas de taro em duas formas de cultivo, solteiras e consorciadas com alface. Dourados, UFMS, $2003-2004$.

\begin{tabular}{|c|c|c|c|c|c|}
\hline \multirow{4}{*}{ Fatores } & \multirow{4}{*}{$\begin{array}{c}\text { Parte Aérea } \\
\left(\mathrm{t} \mathrm{ha}^{-1}\right)\end{array}$} & \multicolumn{4}{|c|}{ Produção de rizomas $\left(\mathrm{t} \mathrm{ha}^{-1}\right)$} \\
\hline & & \multirow{3}{*}{ Mãe } & \multicolumn{3}{|c|}{ Filho } \\
\hline & & & \multicolumn{2}{|c|}{ Comercial } & \multirow[t]{2}{*}{ Não comercial } \\
\hline & & & Grande & Pequeno & \\
\hline \multicolumn{6}{|l|}{ Cultivar } \\
\hline Macaquinho & $5,97 \quad b^{-1 /}$ & $11,63 \mathrm{a}$ & $23,30 \mathrm{a}$ & $12,60 \mathrm{a}$ & $5,99 \mathrm{a}$ \\
\hline Chinês & $7,43 \mathrm{a}$ & $5,80 \mathrm{~b}$ & $12,22 \mathrm{~b}$ & $13,79 \mathrm{a}$ & $4,49 \quad b$ \\
\hline \multicolumn{6}{|c|}{ Forma de cultivo } \\
\hline Solteiro & $6,23 \mathrm{a}$ & $8,52 \mathrm{a}$ & $16,58 \mathrm{a}$ & $12,18 \mathrm{a}$ & $4,05 \mathrm{~b}$ \\
\hline Consórcio & $7,17 \mathrm{a}$ & $8,92 \mathrm{a}$ & $18,94 \mathrm{a}$ & $14,21 \mathrm{a}$ & $6,43 \mathrm{a}$ \\
\hline C.V. (\%) & 17,38 & 17,93 & 27,88 & 17,25 & 23,29 \\
\hline
\end{tabular}

${ }^{1 /} \mathrm{F}, 5 \%$ de probabilidade

A produção de massa fresca de rizomas-mãe das plantas do taro 'Macaquinho' foi significativamente maior que a do 'Chinês' (Tabela 3), mas foram independentes das formas de cultivo. Esses resultados indicam que os sistemas vegetais são capazes de se auto-regular, baseando-se na capacidade de adaptação do organismo individual e das populações (LARCHER, 2000). Isso porque a maximização da produção depende da população empregada em função da capacidade suporte do meio e do sistema de produção adotado (BÜLL, 1993) e da adequada distribuição espacial das plantas na área, em conformidade com as características genotípicas (HARDER,2004).

A produção de massa fresca de rizoma-filho comercial grande das plantas do cultivar Macaquinho foi significativamente maior que a do 'Chinês', mas, a produção de massa fresca de rizoma-filho comercial pequeno mostrou comportamento inverso. Esses resultados também confirmam que a partição dos fotoassimilados é função do genótipo e das relações fonte-dreno (EMBRAPA, 1996; FANCELLI; DOURADO NETO,1996). Além disso, permitem concluir que as plantas do cultivar Macaquinho já tinham alcançado a maturidade e o máximo crescimento, com conseqüente aumento da translocação dos fotoassimilados acumulados na parte aérea para o crescimento e aumento de massa dos rizomas-mãe e, posteriormente, destes para os rizomas-filho (HEREDIA ZÁRATE, 1990a;
HEREDIA ZÁRATE; VIEIRA; LOPES, 2000). Esse fato é confirmado com a semelhança nos percentuais de produção de rizoma-filho não comercial desses clones $(14,30 \%$ para o 'Macaquinho' e 14,72\% para o 'Chinês'), apesar de terem mostrado diferenças significativas quando o taro foi cultivado com ou sem alface (Tabela 3 ).

As razões de área equivalente (RAE) para os consórcios alface com o taro Macaquinho e alface com o taro Chinês foram superiores em 131\% e 83\%, respectivamente, em relação aos cultivos solteiros, indicando que foram efetivos (Tabela 4).

Ao relacionar a renda bruta, observou-se que para o produtor os dois consórcios foram viáveis economicamente, mas, o consórcio alface com taro Macaquinho foi o melhor ( $\mathrm{R} \$ 83.664$ ), porque poderia ter induzido ganho por hectare de $\mathrm{R} \$ 50.664$, $\mathrm{R} \$$ 50.112 e R \$ 48.180 em relação aos cultivos solteiros da alface, do taro Chinês e do taro Macaquinho, respectivamente, e de $\mathrm{R} \$ 21.768$ em relação ao consórcio da alface com o taro Chinês. Os valores obtidos para a RAE e para a renda bruta são coerentes com as citações de Sullivan (2001), Salvador (2003) e Harder (2004), de que, o aumento da produtividade por unidade de área é uma das razões mais importantes para se cultivar duas ou mais culturas no sistema de consorciação, porque permite melhor aproveitamento da terra e de outros recursos disponíveis, resultando em maior rendimento econômico. 
Tabela 4. Massa fresca, Razão de Área Equivalente e Renda bruta da alface e dos taros 'Macaquinho' e 'Chinês', em cultivo solteiro e consorciado. Dourados, UFMS, 2003-2004.

\begin{tabular}{|c|c|c|c|c|c|}
\hline \multirow{2}{*}{$\begin{array}{l}\text { Forma } \\
\text { de cultivo }\end{array}$} & \multirow[b]{2}{*}{ Espécie } & \multirow{2}{*}{$\begin{array}{l}\text { Massa fresca } \\
\left(\mathrm{t} \mathrm{ha}^{-1}\right)\end{array}$} & \multirow[b]{2}{*}{$\mathbf{R A E}^{3}$} & \multicolumn{2}{|c|}{ Renda bruta $(\mathrm{R} \$)^{4}$} \\
\hline & & & & Cultivo & Total \\
\hline \multirow{3}{*}{ Solteiro } & Alface & $22,65^{2}$ & 1,00 & $33.000,00$ & $33.000,00$ \\
\hline & Macaquinho $^{1}$ & 29,57 & 1,00 & $35.484,00$ & $35.484,00$ \\
\hline & Chinês ${ }^{1}$ & 27,96 & 1,00 & $33.552,00$ & $33.552,00$ \\
\hline Consórcio & Alface & $19,92^{2}$ & & $33.000,00$ & \\
\hline $\mathrm{AM}$ & Macaquinho & 42,22 & 2,31 & $50.664,00$ & $83.664,00$ \\
\hline Consórcio & Alface & $21,91^{2}$ & & $33.000,00$ & \\
\hline $\mathrm{AC}$ & Chinês & 24,08 & 1,83 & $28.896,00$ & $61.896,00$ \\
\hline
\end{tabular}

${ }^{1}$ Taro

${ }^{2}$ Massa correspondente a população de 132.000 plantas ha'

${ }^{3}$ Razão de Área Equivalente (CAETANO; FERREIRA; ARAUJO, 1999)

${ }^{4}$ Preço pago ao produtor:

"Pé" de alface $=\mathrm{R} \$ 0,25$ e $\mathrm{kg}$ de taro $=\mathrm{R} \$ 1,20$ Fonte: Vendedores de hortaliças no varejo, em 27-10-2004.

\section{Conclusão}

Pelos resultados obtidos, nas condições em que foi desenvolvido o experimento, concluiu-se que em Dourados-MS foram viáveis os consórcios da alface 'Grand Rapids Nacional'com os cultivares de taro 'Macaquinho' e 'Chinês'. Considerando a RAE e a renda bruta, deve ser recomendado preferencialmente o consórcio da alface com o taro Macaquinho.

\section{Agradecimento}

Ao CNPq, pelas bolsas concedidas e à FUNDECT-MS, pelo apoio financeiro

\section{Referências}

ABRAMO, M.A. Taioba, cará e inhame: o grande potencial inexplorado. São Paulo: Ícone, 1990. 80p.

ANUÁRIO A GRANJA DO ANO. Cará e inhame. São Paulo: Centaurus, 1994. p.30-35,

BARBOSA, A. P. Adubação foliar com fertilizante orgânico em alface cultivada em hidroponia (sistema NFT). In: CONGRESSOBRASILEIRODECIÊNCIADOSOLO,27, 1999, Brasília. Anais... Brasília: SBCS, 1999. (Resumo T042-9).

BÜLL, L.T. Cultura do milho: fatores que afetam a produtividade. Piracicaba: POTAFOS, 1993.301p.

CAETANO, L.C.S.; FERREIRA, J.M.; ARAÚJO, M. Produtividade da alface e cenoura em sistema de consorciação. Horticultura Brasileira, Brasília, v.17, n.2, p.143-146, 1999 .

DIAGNÓSTICO da produção e do abastecimento de hortigranjeiros, produtos agroindustriais e pescado no Estado de Mato Grosso do Sul. Brasília: MA/SDR/PNFC, 1998.334p.

EMBRAPA. Recomendações técnicas para o cultivo do milho. 2.ed. Brasília: Embrapa-SPI, 1996.

FANCELLI, A. L.; DOURADO NETO, D. Milho: fisiologia da produção. In: SEMINÁRIO SOBRE FISIOLOGIA DA PRODUÇÃO E MANEJO DE ÁGUA E DE NUTRIENTES NA CULTURA DO MILHO DE ALTA PRODUTIVIDADE, 1996, Piracicaba. Anais.... Piracicaba: ESALQ/USPPOTAFÓS, 1996. p.1-29

FILGUEIRA, F.A.R. Manual de olericultura: cultura e comercializa;cão das hortaliças. São Paulo, Agronômica Ceres, 1972.451p.

FILGUEIRA, F.A.R. Novo manual de olericultura: agrotecnologia moderna na produção e comercialização de hortaliças. Viçosa: UFV, 2000. 402p.

HARDER, W. C. Produção e renda bruta de rúcula (Eruca sativa Mill.) 'Cultivada' e de almeirão (Cichorium intybus L.) 'Amarelo', em cultivo solteiro e consorciado. 2004. 26f. Dissertação (Mestrado em Fitotecnia) Universidade Federal de Mato Grosso do Sul, Dourados.

HEREDIA ZÁRATE, N. A. Curvas de crescimento de inhame e da variação na composição química e na umidade do solo, considerando cinco populações e cinco épocas de preparo do solo. In: ENCONTRO NACIONAL SOBRE A CULTURA DE INHAME, 2., 1989, Dourados. Anais.... Campo Grande: UFMS, 1990a. p.11-42. 
HEREDIA ZÁRATE, N. A.; VIEIRA, M. C.; GOMES, H. E. Cará, inhame e mandioquinha-salsa na alimentação de frangos de corte. Cerrados, Campo Grande, v. 4, n.8, p.7$11,2001$.

HEREDIA ZÁRATE, N. A.; VIEIRA, M. C., LOPES, J. Produção de rizomas do inhame 'Cem/Um' sob nove populações de plantas em Dourados-MS. Ciência e Agrotecnologia, Lavras, v.24, n.1, p.118-123, 2000.

HEREDIA ZÁRATE, N.A. Curvas de crescimento de inhame (Colocasia esculenta (L.) Schott), considerando cinco populações em solo seco e alagado. 1988. 95f. Tese (Doutorado) - Universidade Federal de Viçosa, Viçosa.

HEREDIA ZÁRATE, N.A. Produção de cinco clones de inhame cultivados no pantanal sul-matogrossense. Horticultura Brasileira, Brasília, v.13, n.1, p.38-40, 1995.

HEREDIA ZÁRATE, N.A. Propagação e tratos culturais em inhame (Colocasia esculenta (L.) Schott) cultivado em solo seco. In: ENCONTRO NACIONAL SOBRE A CULTURA DO INHAME, 2, 1989, Dourados. Anais... Campo Grande: UFMS, 1990b. p. 59-96.

HEREDIA ZÁRATE, N.A.; VIEIRA, M.C.; SILVA, R.M.M.F. Produção de cinco clones de inhame em cinco épocas de plantio, em Dourados-MS. SOBInforma, Rio de Janeiro, v.15, n.2, 1996.

HEREDIA ZÁRATE, N.A.; YAMAGUTI, C.Y. Curvas de crescimento de cinco clones de inhame, em solo "sempre úmido", considerando épocas de colheita, em Dourados - MS. SOBInforma, Curitiba, v.13, n.2, p.23-24, 1994.

INNIS, D.Q. Intercropping and the scientific basis of the traditional agriculture. London: Intermediate Publications, 1997. 179p.
LARCHER, W. Ecofisiologia vegetal. São Carlos: RiMa Artes e Textos, 2000. 531p.

MÜELLER, S.; DURIGAN, J.C.; BANZATTO, D.A.; KREUZ, C.L. Épocas de consórcio de alho com beterraba perante três manejos do mato sobre a produtividade e o lucro. Pesquisa Agropecuária Brasileira, Brasília, v.33, n.8, p.1361-1373, 1998.

SALVADOR, D.J. Produção e renda bruta de cebolinha e de almeirão em cultivo solteiro e consorciado. 2003, Dourados. 16f. Monografia (Bacharelado em Ciências Biológicas) - Universidade Federal do Mato Grosso do Sul, Dourados.

SULLIVAN, P. Intercropping principles and production practices. 2001. Disponível em <www.attra.org/attra-pu/ intercrop.html\#abstratNational >. Acesso em: 3 set. 2003.

TOLENTINO JÚNIOR, C.F.; HEREDIA ZÁRATE, N.A.; VIEIRA, M.C. Produção da mandioquinha-salsa consorciada com alface e beterraba. Acta Scientiarum: Agronomy, Maringá, v.24, n.5, p.1447-1454, 2002.

TRANI, P. E.; GROPPO, G.A.; SILVA, M. C. P.; MINAMI, K.; BURKE, T. J. Diagnóstico sobre a produção de hortaliças no estado de São Paulo. Horticultura Brasileira, Brasília, v.15, n.1, p.19-24, 1997.

VIERA, M.C.; HEREDIA ZÁRATE, N.A.; GOMES, H.E. Produção e renda de mandioquinha-salsa e alface, solteira e consorciados, com adubação nitrogenada e cama de frango em cobertura. Acta Scientiarum: Agronomy, Maringá, v.25, n.1, p.201-208, 2003. 